Article

\title{
How to Maintain the Sustainable Development of a Business Platform: A Case Study of Pinduoduo Social Commerce Platform in China
}

\author{
Wu Zhao ${ }^{1}{ }^{\oplus}$, AnQi Wang ${ }^{1}{ }^{\circledR}$ and Yun Chen ${ }^{2, *}$ \\ 1 School of Economics and Management, Xidian University, Xi'an 710126, China; \\ zhsxwu@xidian.edu.cn (W.Z.); aqwang308@stu.xidian.edu.cn (A.W.) \\ 2 Salford Business School, University of Salford, Salford M5 4WT, UK \\ * Correspondence: y.chen@salford.ac.uk
}

Received: 4 August 2019; Accepted: 29 October 2019; Published: 12 November 2019

\begin{abstract}
At present, the 'platform business model' has indicated innovative potentials not just in traditional industrial sectors such as telecommunications, IT and retail, but also other sectors like social commerce. However, 'Platform' is not static as it is firmed at the beginning. Using Pinduoduo as a case study, this research conducts in-depth interviews and surveys in China to analyze the dynamic change of the platform provider's role for successful platform operation via the lens of platform business models. As a "2.0 generation eCommerce platform", Pinduoduo platform has become the largest social commerce platform in China with continuous growth at a high speed. The study found that stabilisation of the platform has experienced two stages: spread and evolution. At the spread stage, the role of platform provider focuses on forming "incentive to participants" through "Low price + Social contact" strategy and "Gamification + brand channel" strategy. At the evolution stage, the provider's role is transformed into manager of products/services quality and revenue structure. Pinduoduo's quality control is composed of three levels, including front-end quality control, middle-end quality control and back-end quality control. Besides, platform revenue structure strategies are sponsor-type. The purpose of this study is to enlighten the current players in the market on how they might utilize the underlying rationales in framework to further develop their platform business models. From the perspective of a platform, sustainable development of a theoretical framework is proposed based on these findings to facilitate future research in this area.
\end{abstract}

Keywords: platforms business ecosystem; social commerce; sustainability platform; case study

\section{Introduction}

China's eCommerce sector has been dominated by several eCommerce giants such as Tmall (https://www.tmall.com/), Taobao (https://world.taobao.com/) and JD (https://www.jd.com/) for a long time. High customer cost has become the biggest bottleneck in the development of traditional eCommerce, and various eCommerce platforms are looking for breakthroughs [1]. In recent years, the maturity of social media development has offered a potential solution and enabled eCommerce to form the platform based on social networking. The merge of social media and eCommerce has created social commerce which is a new phenomenon in the retail business [2]. Network based marketing has proven to be more cost-effective than traditional direct marketing [3]. Thus the social commerce model may effectively solve the problem of customer cost, and is an important development direction of the eCommerce industry in the future. China's social commerce industry development report points out that since the emergence of social commerce in 2013, it has developed rapidly for five consecutive years [4]. In 2018, the scale of China's social commerce market has reached 1139.778 
billion RMB with an increase of $66.73 \%$ over 2017. The report predicts the social commerce market will reach three trillion RMB in Commerce platforms (such as ador (https://www.ador.com/), yunjiglobal (https://www.yunjiglobal.com/), beidian (http://www.beidianw.cn/), and the huge market growth share in the future indicates that this new economic field has huge potential and business opportunities. Although social commerce has grown rapidly in recent years, and more customers, business partners and investors have joined in this industry, the existing research on social commerce platforms is still limited. Few scholars have the holistic view on platform development strategy and the effect of the platform provider's role on social commerce.

In China, the development of mobile payment technology promotes the growing maturity of the social commerce industry, utilising the full advantage provided by social media channels, such as WeChat. Social commerce platforms, typically represented by Pinduoduo (https://www.pinduoduo. com/), have achieved the growth of gross merchandise volume. Since its establishment in 2015, Pinduoduo has accumulated 400 million users in just three years, undoubtedly becoming the most prominent eCommerce platform in the current Internet market [5]. As the most successful social commerce platform in China, the mode and strategy of Pinduoduo platform are worth studying. In addition, its platform provider plays multiple roles in development of the platform with creative business strategies. Therefore, this paper adopts Pinduoduo as a typical case study to conduct in-depth research on analysis of the platform provider's multiple roles to stabilise a multi-sided platform. The research results mostly confirm the viability of a framework, which causes it to become an analytical tool for the platform provider to guide embedded strategic decision-making in a multi-sided platform. This paper can enlighten the current players in the market and might utilize the underlying rationales in framework to further develop their platform business models that could be especially applicable for new entrants and platform providers with limited capabilities. Beyond that, this paper is a supplement and refinement to the pre-existing theories in terms of a staged-based development model for a multi-sided platform, which makes it more in line with the social commerce platform.

For the rest of this paper, Section 2 is devoted to literature review on the eCommerce platform business module, multiple roles of a platform provider and the business ecosystem. Based on Kim and Han's platform business models, serving as the backbone of a conceptual framework for case study is described in Section 3. Section 4 analyses the primary data collected in the case study and presents the main findings. Empirical and theoretical results are further discussed in Section 5 to answer research questions. The paper is then summarized in Chapter 6 with conclusions and suggestions for future research.

\section{Literature Review}

In the following sections, we highlight past and recent literature on the eCommerce platform business module and investigate the role of multiple roles of a platform provider in it. Then, we explore the concept of the business ecosystem.

\section{1. eCommerce Platform Business Module}

The term 'platform' is used by industrial managers and researchers in various sectors [6]. The platform connects two different user groups to form a network and establish the infrastructure and rules to facilitate transactions between the two parties [7]. A platform strategy creates value in various ways through interactions between two or more different affiliated users in a two-sided market [8], and is likely to continue to grow consistently using the network effect [9]. With the rise of e-commerce, platform has attracted more attention from scholars [10]. The term 'eCommerce platform' is firstly mentioned in Malone's paper referring to a space to realize transactions in a virtual network with the help of electronic information technology [11]. Bakos [12] defined eCommerce platform as an intermediary organization that provides market price information to both parties and improves transaction efficiency. It can improve enterprise productivity and profits, enhance enterprise specialisation and expand market scope [13]. 
eCommerce platform is evolving towards a multilateral platform [14]. Besides supply- and demand-sides, it also gathers complementary parties, distributors, governments, social organisation and other relevant stakeholders [15]. These stakeholders have the right of choice to enter or exit the platform according to its rules and provide complementary services for the platform. As a result, they increase the heterogeneity of platform stakeholders [16]. To connect these multiple stakeholders, a platform provider plays an essential role to maintain the sustainable platform in various aspects, such as quality control, revenue structures and so on [17]. In practice, a platform provider is a connector, matchmaker and market designer. It should not just connect platform participants, but also offer high-quality and personalised products and services to those stakeholders. Kim [17] divides the evolution of the platform into four stages based on the technological change and business model development, namely, the entry stage, the growth stage, the expansion stage and the maturity stage. He also revealed the dynamic role change of platform providers at different stages using multiple case studies (as shown in Figure 1 below). Han [18] suggests there are three stages in the process of platform evolution, namely, the preparation stage, the spread stage and the evolution stage. In the PES model (Figure 2), the preparation stage and spread stage emphasises the strategic planning and environmental analysis while the evolution stage focuses on innovation. In the early stages, the platform needs to attract a certain number of participants to ensure cash flow and content stream. As a result, the policies of incentive to the participants are important factors [19]. After that, in order to support platform sustainable development, the role of platform provider should evolve dynamically with the strategic change of the platform [18].

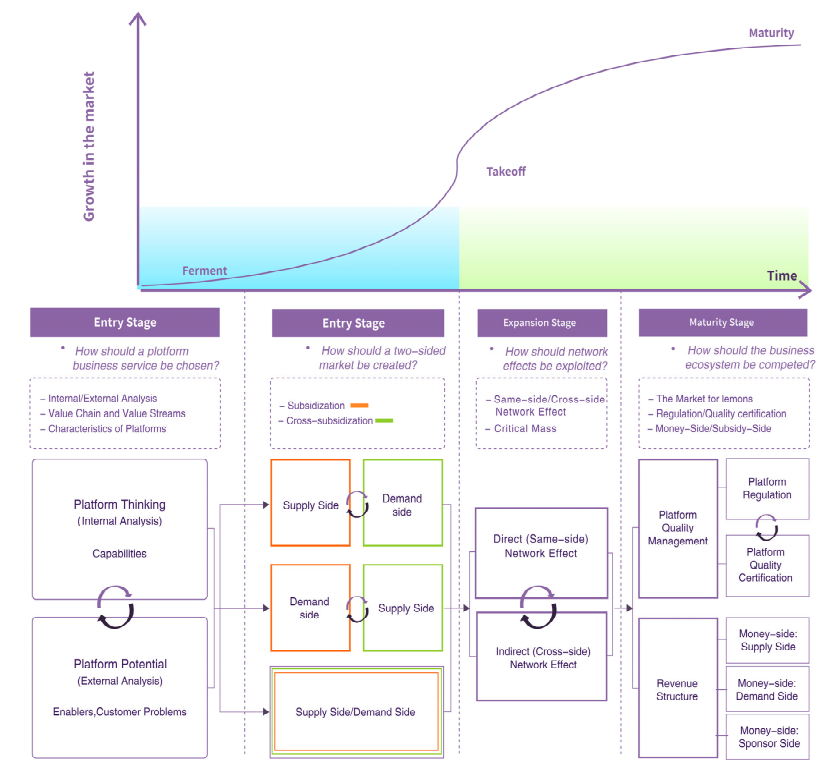

Figure 1. Four-stage model of platform business (Source: [17]).

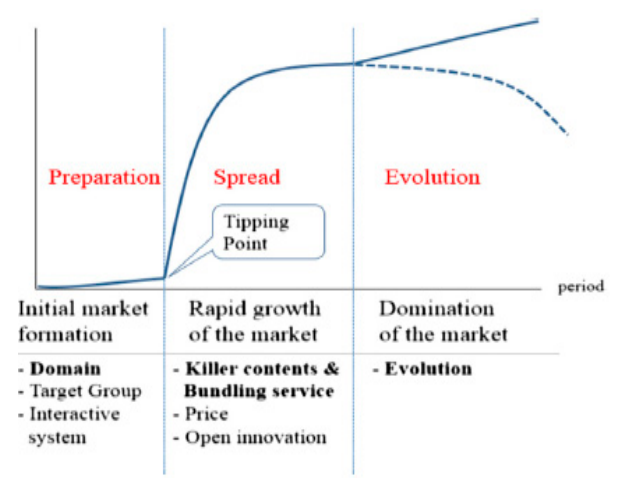

Figure 2. PES curve for platform business (Source: [18]). 
These two models demonstrate some common concentrations on the rationales of platform development. They emphasize that the creation of network effects should be the core target. Kim [17] mentioned that in the expansion stage, the network effects should be exploited. Han [18] considered that at the spread stage, the platform provider should pay attention to the rapid growth of the markets. Thus, strategies on motivation and subsidization are significant at this stage. In addition, since the focused strategy of each stage is very different, it is believed that the roles of platform providers are dynamic and change over time in the platform development process. In the meanwhile, these two models have dissimilar emphases in detailed practical strategies. Kim's model focus is on the quality management and revenue structures, whereas the PSE model pays attention to service development and user co-creation associated with contents [16]. Based on these two models, this paper aimed to research the multiple roles of a platform provider on social commerce.

\subsection{Multiple Roles of a Platform Provider}

Social commerce refers to the operation mode of eCommerce with integration of social networking [20]. It also can be defined as word-of-mouth applied to e-commerce [21]. More fully, social commerce is a subset of electronic commerce that uses social media, online media that supports social interaction and user contributions, to enhance the online purchase experience [22]. Combination of eCommerce and social elements offers a bridge for information communication between merchants and consumers, which leads to more advanced customer attraction channels and business models [23]. It is a new marketing method to sell and promote enterprise commodities by using social forms such as sharing, discussion and user feedback. Through the leading interaction of platform providers, social commerce allows platform stakeholders to get involved in the process of commodity trading, and promotes the sales of commodities by means of spontaneous promotion by consumers. It is a combination of information, technology, business and user interaction [24]. Its ultimate purpose is to promote products or services based on social network interaction and user generated content [21]. From a psychology perspective, users' online shopping is affected by online community information and as a result, the social commerce model is characterised by interactivity and openness [25]. Social commerce could become one of the most challenging research arenas [26]. More and more social commerce platforms have emerged in recent years. Thus, the multiple roles of a platform provider on a social commerce platform are deserving of studying. In this section, the multiple roles of a platform provider are researched from various academic perspectives.

\subsubsection{Early Spread Stage: Incentives to Users}

When the platform is ready to launch, it is necessary to achieve a minimum number of participants [19]. In order to reach the minimum number of users, platform providers need to continuously attract participants. In particular, for multi-sided platform providers of facilitator type, platform providers need to adopt various ways to attract users on the supply-side and on the demand-side [17]. In economics, one can say that an incentive is a benefit, reward, or cost that motivates economic action [27].

The most common incentive for participants is physical motivation, such as an economic incentive. In consideration of product platforms in competitive markets, a lot of participants decide their strategies focusing on their own economic interests. The direct financial incentive, is therefore preferred by the platform members [28]. However, a number of examples readily convey a range of externalities, complexity, uncertainty, asymmetric information and coordination problems which brought severe limits to what could be achieved by extrinsic incentives on their own [28].

In the meanwhile, the motivation for outside players to join in a platform is heterogeneous [29,30], thus non-physical motivation is also important. In the case of collaborative communities, in which complementors are actively involved in value co-creation activities and receive no direct economic incentive, non-physical motivations are preferred. Boudreau have classified motivation for these unpaid complementors into those of intrinsic, reciprocating, and signaling motivation, as shown in 
Table 1 [30]. Different types of motivation have a different relationship with the network effect. Some scholars believe that platforms can attract more and more consumers and service providers because of network effects. Rysman is the first empirical paper to estimate network effects in a two-sided context, namely the market for Yellow Pages [31]. This network effect results from the interdependence between the platform's user needs and those of the service provider [10]. With network effect, the platform's value to any given user depends largely on the number of users on the other side of the network [32]. Generally, network effects in platforms are related to scale, but some scholars have proposed that platform behavior are also important factors affecting the generation of network effects and the creation of platform value [10]. For platform behavior, signaling and reputations motivation can generate the network effects, but intrinsic motivation and reciprocating motivation can not generate network effect [30].

Table 1. Explanations of three types of motivations for unpaid complementors. (Source: [30]).

\begin{tabular}{ccc}
\hline Types of Motivations & Examples of Motivation & Relationship to Network Effects \\
\hline Intrinsic & $\begin{array}{c}\text { Self-interests and self-satisfaction; } \\
\text { Own-use user innovation }\end{array}$ & Not related to networks effects \\
\hline Reciprocating & $\begin{array}{c}\text { Response to peers; Learning } \\
\text { from interaction }\end{array}$ & Not related to networks effects \\
\hline Signaling and Reputational & $\begin{array}{c}\text { Public display and peer adaption } \\
\text { of work activity }\end{array}$ & Related to network effect \\
\hline
\end{tabular}

Besides, scholars start to consider the unique value of "killer contents" in incentives to users. In the PSE model, killer content is regarded as a precondition for platform growth [18]. "Killer content" satisfies the goals and objectives of visitors in exchange for loyalty or buying power [33]. The idea of killer content provides the core product/service or the most attractive feature within a platform [18]. A spread face where killer contents are provided in the early stage of the platform can rapidly cause growth of the market [18]. Han [18] suggested that the more important thing in the platform is to create the interactive system not leaving the platform. If the platform has attractive contents, so called killer content, it can with ease establish an interactive system and the platform can be built together. Beyond that, a platform provides the appropriate content to its users, and a platform can be more competitive by bundling services in order to further engage consumers with killer content. What is killer content for social commerce? This is an issue that is worth thoroughly pondering. However, there is still a lack of research on killer content of social commerce platforms in the existing literature. Thus, we need to compare traditional e-commerce platforms with social commerce in order to find the advantages of social commerce. Its advantage may be the killer content on social commerce platforms.

As shown in Figure 3, the left figure illustrates the traditional eCommerce model. The big circle in the center represents the goods on the eCommerce platform, and the small dots around it represent the buyers. The connection between the two indicates the purchase relationship. The figure on the right shows the mode of social commerce. The big circle represents the commodities and the small circle represents the consumers. The figure shows the process of information transfer through the social network of consumers. Relying on mobile social networking such as WeChat and Microblog, social commerce platforms acquire new users through the sharing and communication between old users. Consumers' purchasing demands will be stimulated at any time in scattered social scenes. Under the mode of social commerce, firms can make more profits by attracting and alluring potential buyers via positive recommendations by existing consumers [34]. The above comparison reflects the characteristics of social commerce. How can social e-commerce platforms use those features to attract users through killer content? This needs to be analyzed with specific cases. Based on Kim's model [17] and Han's model [18] and combined with the summary of incentives to users in existing literature, the first sub-question and proposition can be proposed as follows:

Sub-question 1: How do incentives to participants on the social commerce platform work in the spread stage? 
Sub-proposition 1: Platform providers attract users by physical motivation, non-physical motivation and killer content.
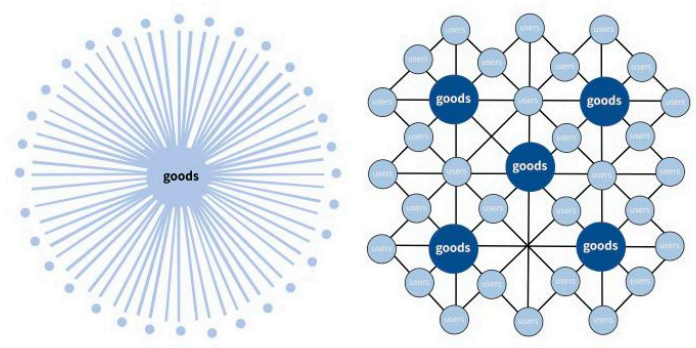

Figure 3. Comparison between traditional eCommerce model and social commerce model.

\subsubsection{Late Evolution Stage: Quality Control and Revenue Structure}

There are some ways to promote multi-participants to achieve a win-win situation in the evolution stage: platform quality control and balanced revenue structure $[17,18,35]$.

A big problem for online transactions is related to information on product quality [36]. The ease of publishing on the Web has facilitated the adoption of this technology by consumers and producers of goods alike [37]. With the help of search engines, consumers can obtain product information and often make purchases with much less effort than through other distribution channels [37]. This results in more product information, on balance, being supplied to consumers than ever before. However, under the disguise of information overflow, there is also information scarcity, a phenomenon that is affecting the market efficiency by creating information asymmetry: both parties do not have the same information [38]. For example, when a vendor offers products online, there is no easy way right now for consumers to know whether the vendor is a reputable one, what his product quality is, or whether it is really a legitimate business [36]. Due to the existence of asymmetric information, it is very difficult for buyers in the electronic market to have full knowledge of the product quality prior to purchase.

Under this circumstance, quality management is essential for a multi-sided platform to provide trust to its multi-sided user. On the one hand, the 'platform regulation' is necessary for quality management [28]. Boudreau and Hagiu [28] insisted that platform regulation can even take the form of managing behaviour after or before they have occurred - 'ex post' or 'ex ante' respectively. On the other hand, Hagiu [39] suggested 'hard certification' and 'soft certification'; the 'hard' method is to limit the advancement of the platform or activities if a certain criterion is not met; the 'soft' method is to provide information regarding product satisfaction or reliability through consumer evaluations. On this foundation, Kim [17] regards it is possible to prevent quality from being degraded using a number of management options that can be represented on a $2 \times 2$ matrix comprising 'Hard-Ex Ante', 'Soft-Ex Ante', 'Hard-Ex Post' and 'Soft-Ex Post' (see Figure 4). In some circumstances, only one of these options is possible although in others it is impossible to use them in combination.

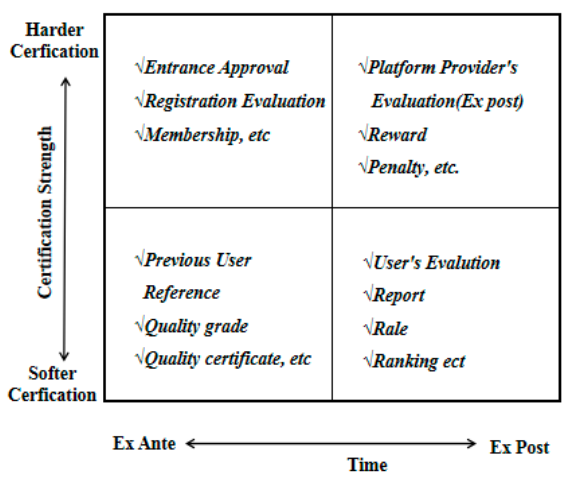

Figure 4. Platform quality management $2 \times 2$ matrix (Source: [17]). 
A pertinent research question thus arises:

Sub-question 2: How is it best to conduct quality control on the social commerce platform?

Sub-proposition 2: Quality control can be accomplished by a mixed method of strategies in terms of categories and several strategies are selected to be combined according to platform needs.

The ultimate goal of any type of business is to generate revenue, and platform businesses are no exception [17]. Even if the platform has developed and grown, a platform business cannot be maintained if profit is not stably produced. Therefore, the platform leader must create 'economic incentives for ecosystem members' [29]. However, since the rate of growth might be slowed by profit creation, companies must judge their profit models carefully through considering the platform strategy. Rochet and Tirole [40,41], Caillaud and Jullien [42] and Armstrong [7] each provide a theoretical framework for two-sided markets to explain how the price structure is determined when either a monopoly platform sets prices or two platforms compete. Based on those theories, platform companies need to design the price structure that is imposed on the members with the aim of making the entire business ecosystem grow continuously and producing profits of their own [17]. Particularly in accordance with price elasticity, platform providers should begin separately to identify the money-side and subsidy-side participants $[17,43]$. Platforms need to consider each side group's price sensitivity. The money-side refers to those platform participants who pay for the service - a group with relatively low price elasticity. The subsidy-side refers to those users who benefit from the platform, and have relatively high price elasticity. Owing to the difference between the money-side, the revenue structure strategies can be divided into three categories, as shown in Table 2.

Table 2. Platform revenue structure strategies (Source: [17]).

\begin{tabular}{ccc}
\hline Revenue-Structure & Money-Side & Subsidy-Side \\
\hline Supply-type & Supply-side & Demand-side \\
\hline Demand-type & Demand-side & Supply-side \\
\hline Sponsor-type & External entities (sponsor) & Demand- and Supply-side \\
\hline
\end{tabular}

Revenue measures the ability of the firm to translate the value it offers to its customers into money and therefore generate incoming revenue streams [44]. The first revenue structure is the supply-type. For these two companies, the demand-side cannot produce profits, and the price sensitivity from the supply-side is different, so the money-side is the supply-side. The second is the demand type. The supply-side cannot produce profits. Thus the supply-side is the subsidy-side. The last is models deriving profits from them are sponsor-based business models which is put forth by Casadesus [45]. This model is appropriate when the price competition is fierce or when both the supply- and demand-sides have high price elasticity [17]. Thus users are from the subsidy-side and the advertisers are from the money-side. Many organizations look towards advertising as the main source of revenue. It is natural for these web sites to host banner ads, which generate huge revenue to support their operations [46]. By combining data analysis with automated customization techniques, platforms earn revenue from targeted advertisements and recommendations appearing as banners or running in sidebars [47]. It is important to mention that ICT have had an important impact on pricing and have created a whole new range of pricing mechanisms [48]. Meanwhile, social networks consist of large numbers of individuals who are potential content generators and a massive source of information [49]. Crowd-sourcing utilizes the potential of networked web users to generate new ideas, advertise, and create added value for a little (or no) cost while increasing effectiveness by understanding customer needs, identifying potential customers, and building loyalty [49]. Is the little (or no) cost of advertising or customer cost having an impact on the platform revenue structure strategies?

Thus a problem has arisen:

Sub-question 3: How is it best to apply a suitable revenue structure on the social commerce platform? 
Sub-proposition 3: For a multi-sided social platform, a sponsor-type revenue structure can be applied.

The study on the largest social commerce in China (i.e., Pinduoduo) is beneficial to complement the lack of existing research on the role of social commerce platform providers to engage stakeholders and build an inclusive business ecosystem. The rest of this paper will be devoted to a deep investigation of Pinduoduo social commerce platform to test whether the existing theories which derived platform business models are applicable to social commerce platforms $[17,18]$. Compared with traditional eCommerce platforms, this research aims to analyse how the role of the platform provider of the social commerce platform realises dynamic change.

\subsection{Business Ecosystem}

After building a two-sided market, a business is required to complete its ecosystem to enable itself to continue its platform business in the market. Even if the business has already been established in the market, if there are no continuous participants' supports in the business ecosystem, the business will fail [17]. Moore is the first scholar to propose the concept of "Business Ecosystems" [50]. The business ecosystem is the environment in which all relevant participants in the process of enterprise value creation trade with them. Its main components include entrepreneur, consumers and market [49]. The entrepreneur refers to the economic unit which produces the product and the service in the system. The consumers are economic units transforming products and services into production elements with the capability of generating knowledge, technology and systems evolution. The market is the place where the members of the system trade between economic units. Its characteristic work is to promote the flow of wealth and the exchange of resources in the system, and to ensure the dynamic balance of the entire commercial ecosystem [50]. Roundy and Brockman suggested [51] three factors that affect the business ecosystem: entrepreneurs' intentions, consistency of entrepreneurship activities and resource injection. It is believed by researchers that the enterprise operation mode is the primary consideration in the development of a business ecosystem and the entrepreneur is the key [52-54].

In recent years, much research has been devoted to study of a business ecosystem with inclusive innovation [55-57]. Inclusive design is integrated into the ecosystem so that people excluded from the digital world can join the ecosystem in an equal way [55]. The initiative of the business ecosystem is to interact with and derive value from external entities [58]. Each subject related to the ecosystem has direct interaction or subordination [59]. As a result, an inclusive business ecosystem must establish and maintain stable communities externally and reinforce entrepreneurs' intentions, consistency of entrepreneurship activities and resource injection internally [51].

\section{Research Design and Methodology}

This chapter includes the adopted conceptual framework, methodology, data collection and data analysis.

\subsection{Conceptual Framework}

This research adopts a deductive approach. It provides an effective method of studying contextual phenomena by changing from a general model to a specific case [60]. In deductive research, theoretical framework is important which can serve as a guideline for hypothetical reasoning [61]. Based on Kim and Han's platform business models $[17,18]$, the conceptual framework is proposed as Figure 5 below, considering characteristics of social commerce as discussed in the previous chapter. 


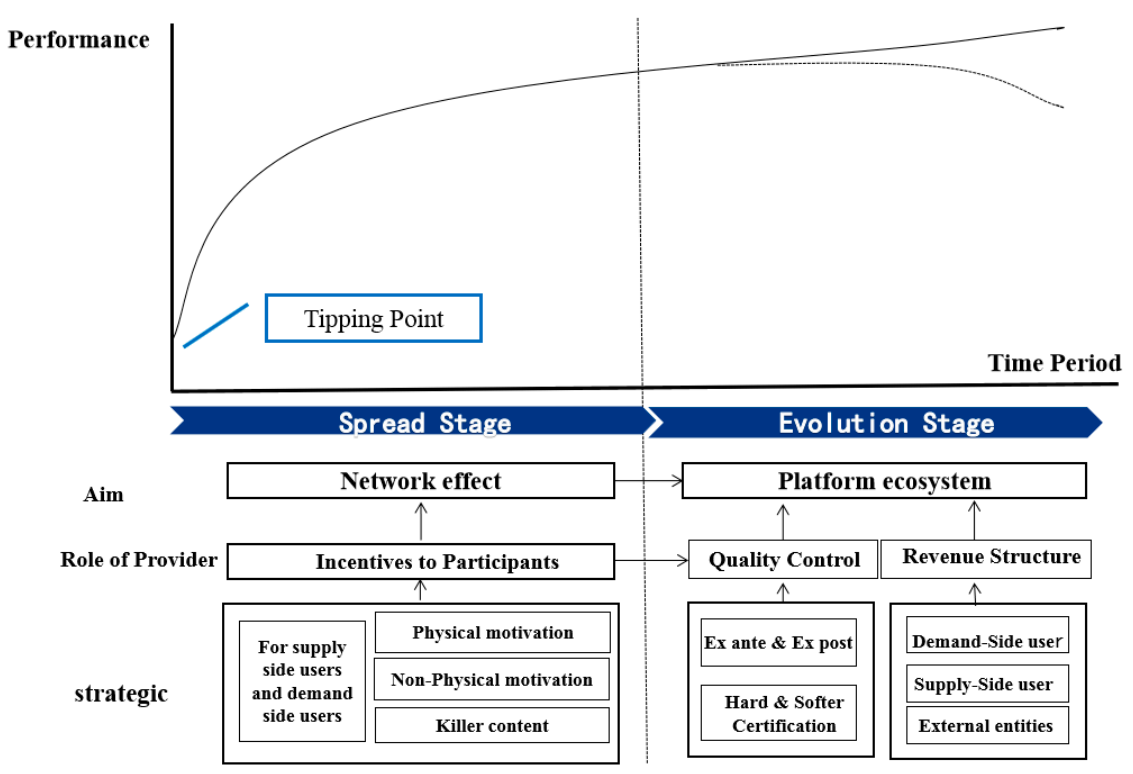

Figure 5. Conceptual framework.

In this diagram, the horizontal axis represents the time line, while the vertical axis represents the platform performance. It can be seen from this diagram that the main aim, strategy, and role of the platform provider changes over time along with the development of the platform. The framework mainly bases on the previous work of Kim [17] and Han et al, [18] and chooses the two stages of spread and evolution to study. In Kim's original framework, there were four main stages. In the meanwhile, there were three main stages of PSE model. The main purpose of this study is to study the multiple roles of platform providers after the tipping point. Therefore, spread and evolution are chosen as the focus of the study. In the spread stage, the main role of platform providers is to motivate multi-sided participants and form a stable business platform. In the evolution stage, the platform business begins to emerge and contributes to the establishment of the business ecosystem to maintain long-term competitiveness and customer relations. Thus, the platform provider role shifts to quality control and the development of a revenue structure. It can be argued that the platform provider strategy contributes to the achievement of the phased objectives in each stage. On the basis of the three sub-questions raised in the literature review, this conceptual framework indicates the key research question and hypothesis, as below:

Question: How does the role of the social commerce platform providers change over time?

Proposition: In the spread stage, the platform provider is mainly responsible for incentive to the participants. In the evolution stage, the platform provider is mainly responsible for quality control and balanced revenue structure design.

\subsection{Research Methodology}

\subsubsection{Case Study}

The case study is selected as the research methodology in this study, for two reasons: Firstly, this study is an explanatory study. The case study can provide profound observations on specific social phenomena, and the case study can verify the statement of problems, which not only conform to the method of deductive reasoning, but also can improve the effectiveness of the theory [62]. Secondly, social commerce is a new emerging industry. Most Chinese social commerce companies were established between 2014 and 2017, so development time of this kind of business model is relatively short. The limited data in large databases make it difficult to obtain time series data. In addition, from the perspective of platform research, the participants of platform ecology are dynamic and temporary, which makes it difficult to make statistics. Case study methodology is for empirical 
research. It supports the study of ongoing phenomena without breaking away from the real life environment [62], which is suitable for this research.

Miller [63] divided the case types into a single case study and multiple case studies according to the number of used cases in the study. According to the differences of case functions in the study, research can be divided into exploratory case study, descriptive case study and explanatory case study. Combining these two classifications, six different types of case studies can be formed as shown in Table 3 below.

Table 3. Case studies (Source: [63]).

\begin{tabular}{cccc}
\hline & Exploratory Case Study & Descriptive Case Study & Explanatory Case Study \\
\hline Single case study & $\begin{array}{c}\text { Exploratory Single Case } \\
\text { Study }\end{array}$ & $\begin{array}{c}\text { Descriptive Single Case } \\
\text { Study }\end{array}$ & $\begin{array}{c}\text { Explanatory Single Case } \\
\text { Study }\end{array}$ \\
\hline Multiple case studies & $\begin{array}{c}\text { Exploratory Multiple } \\
\text { Case Study }\end{array}$ & $\begin{array}{c}\text { Descriptive Multiple } \\
\text { Case Study }\end{array}$ & $\begin{array}{c}\text { Explanatory Multiple } \\
\text { Case Study }\end{array}$ \\
\hline
\end{tabular}

This research conducts a single exploratory case study in order to practically illustrate the periodical strategies. It uses "incipiency doctrine" and attempts to explain "why" and "how" through the construction and verification of a theoretical framework in a specific situation.

\subsubsection{Rationale for Case Selection}

Due to the aim and objectives of the research, there are several criteria for case selection: (1) The selected platform should be multi-sided which involves two or more sides of participants; (2) The selected platform should be a rapidly developing social commerce platform; (3) The selected platform should be the most representative of the social commerce platform in China. According to these considerations, Pinduoduo, the largest social commerce platform in China, is chosen as the case study for this research.

Established in September 2015, Pinduoduo integrates the concept of entertainment and sharing into the social commerce operation under the concept of human-oriented. It is the largest social commerce platform in China and the third largest eCommerce platform in China, just behind Alibaba and JD. Until March 13, 2019, the number of active buyers of the Pinduoduo platform has reached 415 million annually and its gap with Alibaba is shrinking. The average time spent by each active user on Pinduoduo platform has reached 4 hours and 20 minutes per month, which has surpassed any other eCommerce company in China [64].

\subsubsection{Data Collection Method}

In this research, semi-structured interview and focus groups are adopted to collect primary data from Pinduoduo step by step. The stratified random sampling technique is used to choose participants, as indicated in Figure 6 below.

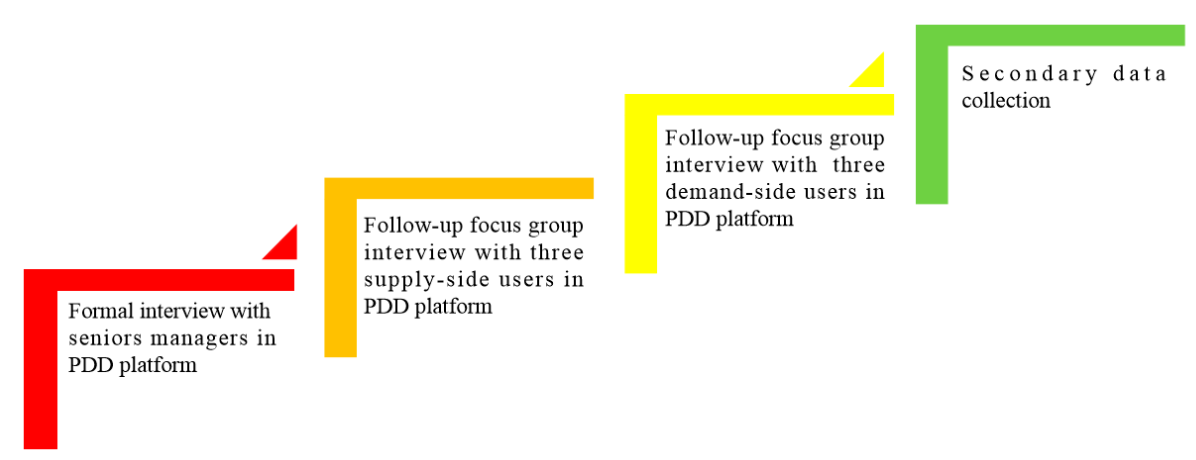

Figure 6. Primary data collection process (method (Source: the author). 
At an early stage of data collection, three senior managers of Pinduoduo platform who are familiar with the platform operation and management, were randomly selected for interviews from the researchers' social network. Three senior managers were interviewed at different times to ensure the integrity of access to information (See Table A1 in Appendix A).

Following the interviews with senior executives, focus groups were conducted with both the supply- and demand-side of the platform. Participants from the supply-side were selected according to the monthly sales volume and product type. According to the monthly sales volume, supply-side is divided into three classifications: 1000-9999 (inclusive) RMB, 10,000-30,000 (inclusive) RMB and more than 30,000 RMB. The product types on Pinduoduo's supply-side are divided into the ten classifications: seasonal women's wear, brand men's wear, global cuisine, hot-selling shoes and bags, home furnishing department stores, beauty, makeup and skin care, home appliances and digital products, maternal and child care, home textile and home furnishing, and outdoor sports. The number of 30 suppliers was randomly selected, three from each of these ten product divisions but with different monthly sales volume. For the purpose of this study, researchers finally grouped those suppliers who provide different products but with the same monthly sales volume into one group. As a result, 30 suppliers were reorganized into three focus groups for the next stage of primary data collection. On the other hand, participants from the demand-side were selected according to the amount of annual consumption and their regions. According to the amount of annual consumption, users are divided into three stratifies: less than 1000 RMB, 1000-4999 (inclusive) RMB and more than 5000 RMB. Because of the vast territory of China and the great differences in consumption habits in different areas, 36 demand-side users were randomly selected from eastern region, central region and western regions of China, 12 from each region with different levels of annual consumption. Finally, these 36 selected users were reorganized into 3 focus groups according to the region. The focus group was conducted on WeChat because of different geographical locations of the participants. The structured focus group protocol is shown in Tables A2 and A3.

Collecting data from multiple data sources and across different time periods can strengthen triangulation and support research aims more comprehensively [65]. Besides the primary data collection discussed above, the research also integrated secondary data such as historical market research reports and the company's documents on Pinduoduo. It is believed that triangulation of data collection can greatly improve the validity of measurement results from exploratory single case study research.

\subsubsection{Data Analysis Method}

In this study, the proposed theoretical framework is analyzed by pattern matching data analysis method. The logic behind this method is to compare the empirical results with the ones predicted by theories and hypothesis, find mutual agreement between the models, and indicate internal validity of research [66]. For exploratory case studies, the expected pattern between specific variables is defined prior to data collection. In this research, the steps of data classification and analysis are as follows: (1) Create a coding scheme to categorise and unitise data (See Figure A1 and Table A4). (2) Recognise the relationship between categories. (3) Compare the observed pattern in practice with the theoretical pattern.

The overall roadmap of this research is indicated in Figure 7 below. 


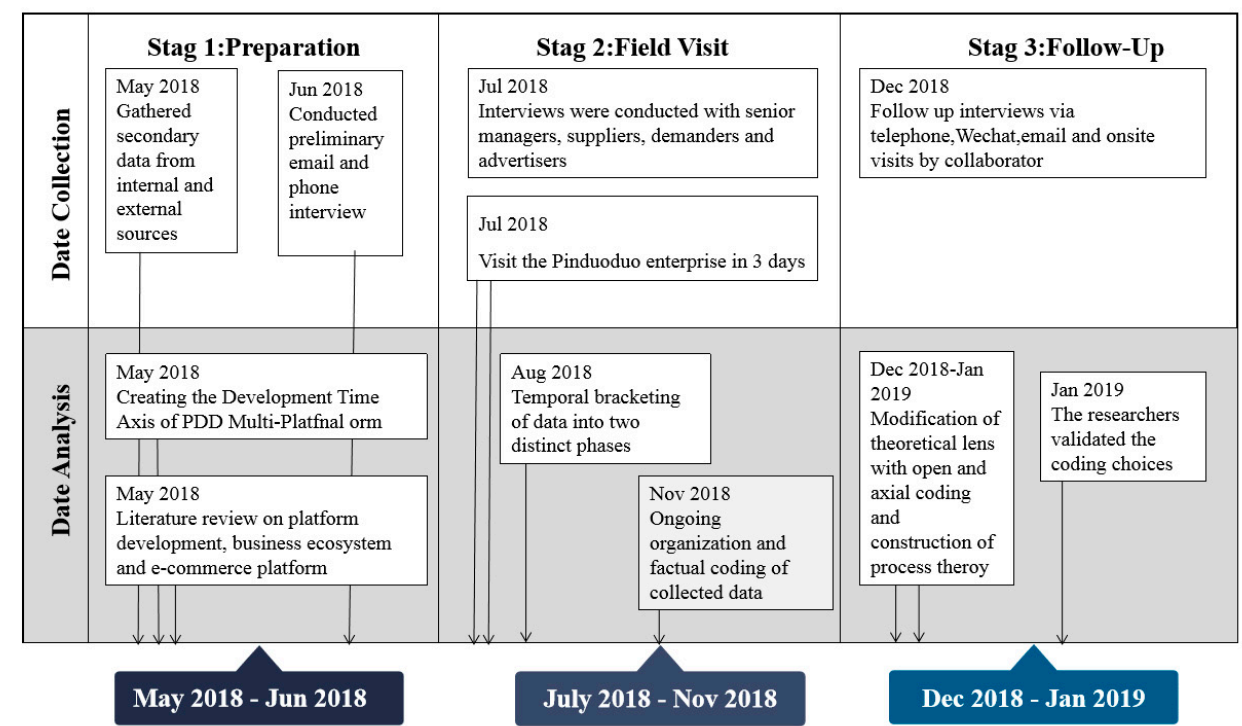

Figure 7. Research road map (Source: the author).

\section{Findings}

\subsection{Findings from Secondary Data Collection: Pinduoduo in Business Ecosystem}

This section introduces the basic information and features for Pinduoduo platform according to the secondary data.

Pinduoduo was founded in the year of 2015. The number of users exceeded 100 million in September 2016. In the meanwhile, Pinduoduo has amalgamated with a company named Pinhaohuo, and then formed the Pinduoduo company today. investors such as Tencent give Pinduoduo platform more than $\$ 100$ million in investments [67]. Since its establishment, Pinduoduo has rapidly been one of the Chinese e-commerce giants. Its business model is different from the $\mathrm{C} 2 \mathrm{C}$ business model of Taobao and the B2C business model of JD. Under the business model of $\mathrm{C} 2 \mathrm{C}$, consumers can buy goods at a lower price by encouraging people around them to group-buying. Since its establishment in a short period of two years, Pinduoduo's users have reached 300 million (as shown in Figure 8).

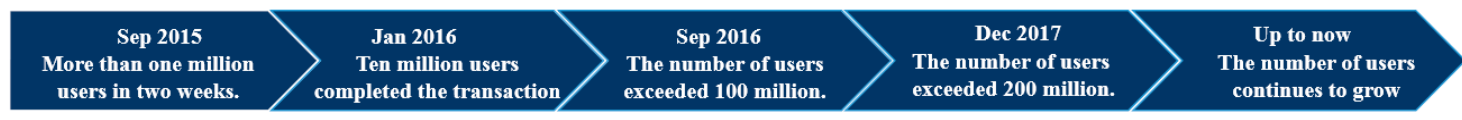

Figure 8. Platform user growth (Source: the author).

The value of platform is to make a "match" between supply-side and demand-side. Pinduoduo is aimed at meeting the need of the people at the bottom of the pyramid. Thus the platform was designed on the basis of the cognitive characteristics and consumption behavior characteristics of the people at the bottom of the pyramid.

The development process of Pinduoduo can be divided into two stages according to the change in strategy:

- The early stage (2015.9-2018.7) is the spread stage of the platform. Relying on the feature of "social + eCommerce", Pinduoduo platform not only successfully attracted more than 1 billion active users of Wechat, but also caught the market of long tail. Since Wechat only opens its traffic pool to the Pinduoduo platform, it avoids the problem which was mentioned by Kim. The question he mentioned was, as more social commerce firms have joined the industry, fierce competition has ensued [22]. The biggest contradiction in this stage is online supply chain control and merchant supervision. The negative comments received are mainly concentrated towards the problem, 
such as the goods have not been received, a poor product quality, existing fake and inferior commodities in the platform and so on.

- The later stage (2018.8-present) is the evolution stage of the platform. Pinduoduo was listed on Nasdaq on 26 July 2018. However, in August 2018, Pinduoduo was held accountable by the Shanghai government and was asked to solve problems proposed by the users in spread stage. Since then, Pinduoduo has paid more attention to the quality management and revenue structure. In the stage of expansion, by providing differentiated services to users and adding platform components, Pinduoduo has been transformed from a social commerce platform to an inclusive business ecosystem (as shown in Figure 9 below).

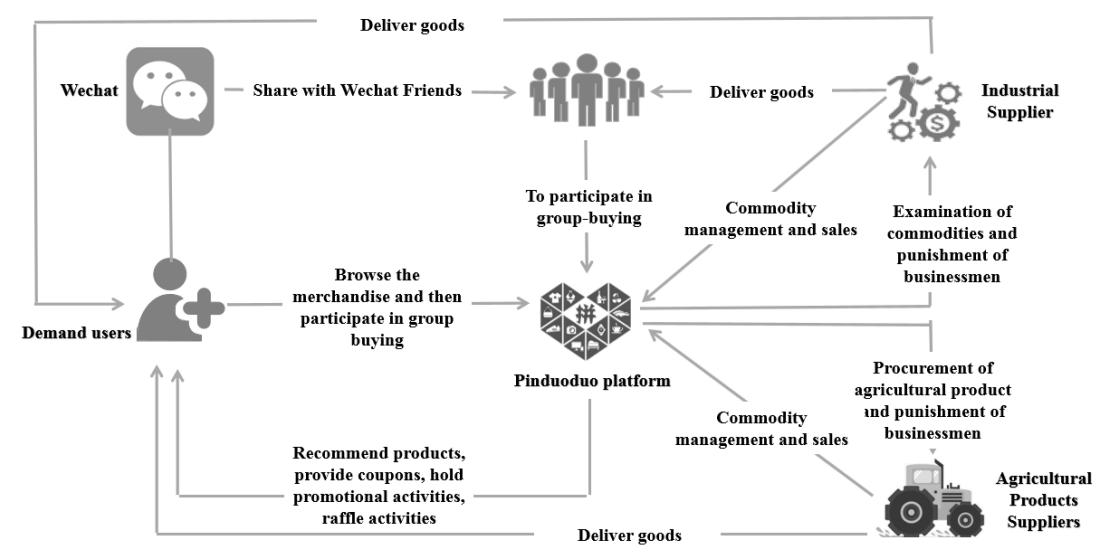

Figure 9. Pinduoduo platform (Source: the author).

With this background, empirical study investigates further on dynamic changes of the platform provider's role, which is discussed in the following session.

\subsection{Findings from Primary Data Collection}

According to the interview with three senior managers, 30 supply-side participants and 36 demand-side participants of the Pinduoduo platform, the researchers found that with the platform development, the platform provider has different practical strategies.

\subsubsection{Spread Stage: Incentives for Participants}

As shown in Table 4 below, the motivation strategies of Pinduoduo can be divided into two types at its spread stage.

Table 4. Motivation strategic in Pinduoduo (Source: the author).

\begin{tabular}{ccc}
\hline & $\begin{array}{c}\text { Focus of Platform Provider (1) } \\
\text { Low Price + Social Contact }\end{array}$ & $\begin{array}{c}\text { Focus of Platform Provider (2) } \\
\text { Gamification + Channel Branding }\end{array}$ \\
\hline Demand-side strategies & $\begin{array}{c}\text { Killer content: } \\
\text { Provide low-priced products and } \\
\text { easy-operating functions for the people } \\
\text { at the bottom of the pyramid }\end{array}$ & $\begin{array}{c}\text { - Killer content: } \\
\text { Duoduo Orchard game }\end{array}$ \\
\hline Supply-side strategic & $\bullet$ Economic incentive & Signaling and reputations incentive \\
\hline Motivation Strength & High & High \\
\hline
\end{tabular}

"Low Price + Social Contact" Strategy

Pinduoduo platform believes that there are huge business opportunities in the people at the bottom of the pyramid. (i.e., "Bottom of the Pyramid" - BOP, referred by [68]). By meeting the needs of this group, companies can not only obtain a pecuniary advantage, but also create social value by 
improving the quality of life for the people at the bottom of the pyramid. Guided by this theory, Pinduoduo takes the BOP group as the main demand-side users from the very beginning.

In the early stage of platform spread, the characteristics of BOP group's consumption behavior were fully analysed by the company. The findings are mainly reflected in two aspects: First, BOP group tends to consume according to their daily needs, spend as little money as possible each time, and are very sensitive to price. Second, BOP group will only consume when the price falls into the price range they can accept and the product meets their basic needs. Based on the analysis result, "killer content" were designed to attract users from the demand-side. Pinduoduo platform's killer content for the demand-side at spread stage is to provide low-priced products and an easy-operating function for the people at the bottom of the pyramid. From the perspective of demand-side users, the low-priced products and easy-operating function are the most attractive points for demand-side users.

- Group Buying: Compared with competitors, the group buying mode employed by Pinduoduo provides lower price products for customers. Every kind of good on Pinduoduo platforms can be purchased through the mode of "buying direct" and the mode of "group buying". Yet if the consumer chooses the mode of group buying, they are able to buy the product at a price lower than the market price. The people at the bottom of the pyramid are extremely price sensitive [69]. Thus they naturally choose the mode of "group buying". Often, the active users who want to buy goods at the lowest price will become a leader, and attract passive users to participate in group buying, as shown in Figure 10 (Source:ThoughtWorks company). Meanwhile, Pinduoduo platform summarizes the customer demands and feedback to the supply-side, which can reduce any intermediate links and obtain the price advantage.

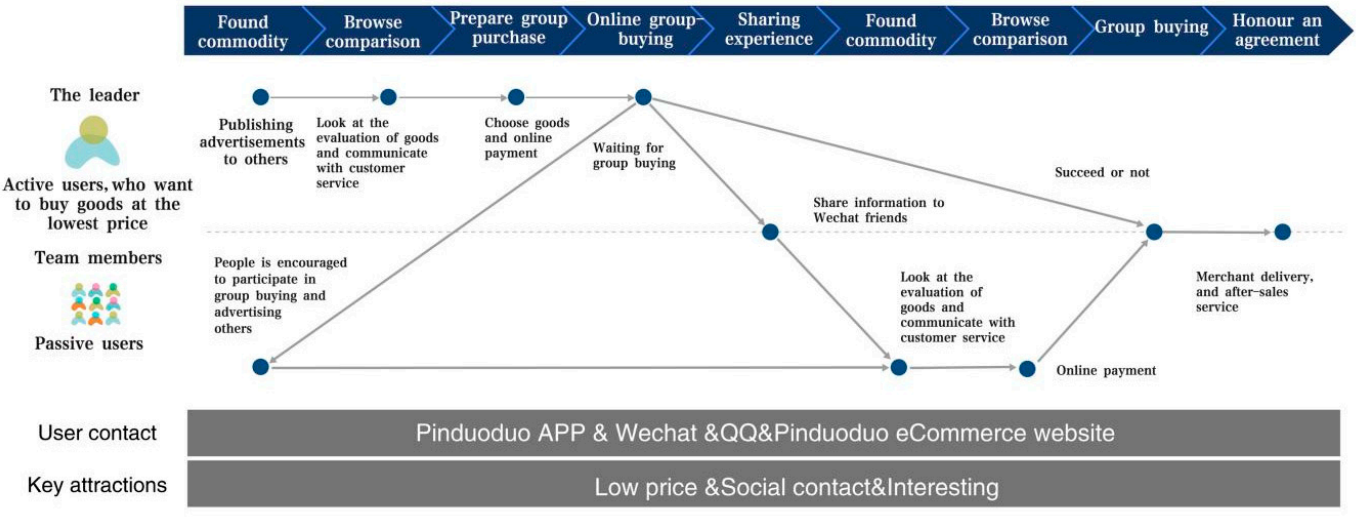

Figure 10. Indicates the purchase process on Pinduoduo platform based on empirical study.

- Rapid Information Transmission through Social Media: Information transmission through social media not only helps the platform reduce the average customer cost and then reduce the price of the product, but also provides an easy-operating function for the people at the bottom of the pyramid. This is because the consumers only need to open the website link of the commodity purchase sent by their acquaintances in WeChat and they can directly purchase this commodity. It does not require a tedious search and operation process which are in line with the characteristics of the people at the bottom of the pyramid who are less educated and unfamiliar with the Internet. Social networks consist of large numbers of individuals who are potential content generators and a massive source of information [49]. According to people's role in information transmission on Pinduoduo platform, they can be divided into four categories: (1) super-star, (2) key opinion leader (referred to as KOL), (3) a location-based relationship related parties (referred to as LBS related parties) (Such as fellow villagers/neighbors), (4) friend of a friend (referred to as FOAF), as shown in Figure 11 below. The importance of the relationship has been highlighted as a major marketing ingredient of success for any business enterprise [70,71]. In a sense, the role of social media enabling customers to talk to one another is an extension of traditional word-of-mouth 
communication [72]. It is particularly worth mentioning here that compared with those on larger incomes, people at the bottom of the pyramid tend to create a stronger sense of community and social network, based on mutual help [73]. On the basis of the above theory, Pinduoduo platform encourages consumers to take the initiative in attracting potential users. In order to reach the minimum number of people who are required for group-buying and then make themself enjoy lower prices, people at the bottom of the pyramid usually share advertisements of group-buying through social media, such as WeChat. Meanwhile, people tend to have stronger ties with those more like themselves [74]. Therefore, the shared commodity information can quickly flow to the target groups with corresponding consumer preferences, and find the potential consumers.

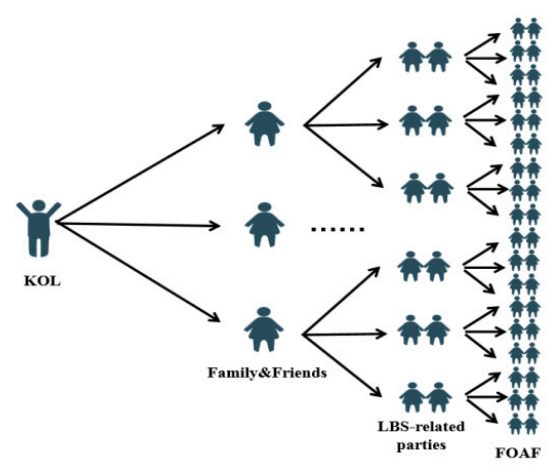

Figure 11. The way of social communication of commodity information on the platform.

For supply-side, the platform provider applies a low-priced entry threshold to attract small and micro enterprises. It is an economic incentive for the supply-side. To set up a shop on Pinduoduo, a supplier only needs to pay a deposit of 1000-2000 RMB to the platform provider. It brings the Pinduoduo platform economic incentives for the supply-side compared with other platforms. For example, JD requires a deposit of 30,000 RMB and a service fee of 12,000 RMB, if an enterprise wants to enter the platform.

\section{"Gamification + Brand Channel" Strategy}

From the perspective of service marketing, gamification was to be defined as "a process of enhancing service with affordances for gameful experience in order to support user's overall value creation" [75].

For users on the demand-side, Duoduo Orchard game then became the killer service provided by Pinduoduo platform that provided further rapid growth. Duoduo Orchard game is a new type of service to blend gaming and social network service (SNS) features to build online connection. In April 2018, Pinduoduo platform launched a game named "Duoduo Orchard", which regarded systems that require an active involvement by the consumer. Through sharing, browsing and purchasing of goods, the users can get water droplets which they can use to water the fruit trees on the platform. When fruit trees grow up, Pinduoduo will post the user a box of real fruit. The reason why the platform regards Duoduo orchard game as killer content is that gamification's effect might be felt throughout the consumer decision process [76]. Gamification has already become an important component of many mobile service offerings as firms seek to enhance customer enjoyment, engagement, and retention [76]. Gamification executed on the mobile platform has the potential to affect an essential set of retailing outcomes, to entertain customers, to accelerate a repurchase, to retain customers, and to contribute to in-store engagement [76]. Thus, Duoduo Orchard game is one of the most essential killer contents of Pinduoduo platform.

For users on the supply-side, signaling and reputational motivations should have the potential to intensify and stimulate greater complementor development and investments with growing platform usage because it increases the size of the potential audience for signaling one's work activity, outputs 
and attendant accolades [30]. Economic models based on Nelson's work show that an established brand name can signal high product quality [77-79]. Essentially, high quality producers advertise their brand heavily, but only expect to recoup the cost of the advertising from many repeat purchases [37]. However, at the same time, manufacturers of high quality products distribute through retailers with a strong reputation (reputable retailers), while manufacturers of low quality products distribute through retailers with no reputation (discounters). In this way, even if high quality manufacturers have no reputation of their own to post as bond, they can signal quality by posting the reputation of the retailers [80]. Based on those theories, Pinduoduo platform downplays the brand effect of the product. This means, the product itself has no brand advantage, but the platform unique channel represents the brand which make consumers believe that the industrial products and agricultural products sold on the platform represent good quality, design and favorable prices. It is a typical example of signaling and reputational incentive to the supply-side.

Pinduoduo platform also focused on production and sales of agricultural products. Owing to the low levels of education and a relative scarcity of production skills, a lot of people at the bottom of the pyramid have to engage in agricultural-related productive labor [81]. Meanwhile, it is difficult for people at the bottom of the pyramid to get relevant market information the first time, thus, those people could not judge the most suitable quantity of production and the most suitable time for sale [82]. Even worse, the people at the bottom of the pyramid usually have no choice but to sell their produce to local middlemen. In this process, they not only have to accept the procurement price at a low level, but also have been treated with no respect [83]. To solve these problems, Pinduoduo collects consumer demand through the group-buying model and to convey the information to farmers. Based on this market information, farmers can compare production and prices with their counterparts across the country and sell their products to consumers at the market price. This act also improves the reputation of farmed products.

\subsubsection{Evolution Stage: Quality Management}

As the number of users continues to increase, negative effects are generated. Therefore, the role of Pinduoduo's platform provider shifts to quality management in evolution stage. Additionally, regulations on quality control change from loose to strict.

In the spread period, less approval is required for the user to enter the platform. Users on the demand-side only need to submit basic personal information and supply-side users only need to pay a small amount of the registration fee. The senior manager in Pinduoduo platform stated that the quality of the product had indeed degraded due to the rapid growth of the platform's user base.

With increasing platform components and content, the platform provider has strengthened quality control. For the people at the bottom of the pyramid, they don't need the best product, but need a good enough product [84]. For these people, their marginal benefit declines quickly [85]. Thus, the platform went to small and medium-sized enterprises to keep the key products performance and exclude high-end functions to better meet the demand of BOP users. In order to reach this goal, the "new brand strategy" was proposed. The new brand strategy is a systematic plan initiated by Pinduoduo which focuses on the growth of small and medium-sized manufacturing enterprises. Armed with this strategy, Pinduoduo has gradually supported 1000 factory brands in all sections of the economy [64]. These enterprises have similar problems and difficulties: they have been the original equipment manufacturer for foreign brands for a long time, and are the upstream enterprises of the international supply chain. They have excellent production quality but without a famous brand in China. The platform helps them to embrace the huge domestic market, and create brands at the lowest cost. In this strategy, the harder certification combination with the softer certification is realized. According to the time and contents, quality control is divided into three levels: front-end quality control, middle-end quality control and back-end quality control:

- Front-end quality control - the platform achieves transparent production through the "visual platform" in the form of a live broadcast. Consumers can see the whole process of product 
manufacturing. In the process of a live broadcast, consumers can comment at any time, and those who have bought can also share their user experience, providing a beneficial interactive environment for consumers;

- Middle-end quality control - all production information of the factory is synchronised to the platform for record, and the full line of the commodity will be traced to realise 'quality upgrade'. The platform promises that the products will be inspected by any third party. If consumers find problems with the products, the platform will refund the merchants ten times of the historical total sales amount of the products involved, and compensate all the fines to the consumers;

- Back-end quality control - based on analysis of a large amount of data obtained from BOP groups, the platform helps small micro enterprises keep the key products performance and exclude high-end functions to better meet the demand of BOP users to realise 'demand to upgrade'.

\subsubsection{Evolution Stage: Revenue Structure and Value Chain}

Pinduoduo has designed different pricing strategies for various users. It is suggested that the revenue models employed in Pinduoduo are relatively complicated in respect to their current evolution stage. The platform provides subsidies to users on the demand-side for inclusive purposes. e.g., As the $\mathrm{BOP}$ group is very sensitive to price, thus users on the demand-side can register for free and browse and query product information. At the same time, the platform offers irregularly and randomly issued cash subsidies or coupon subsidies to users on the demand-side; For the user on the supply-side, the platform provides a relatively lower registration fee and preferential prices. The main revenue of Pinduoduo consists of profit sharing, advertising, services provided to merchants and transaction commission. Thus, models deriving profits from them are sponsor-based business models. However, as the representative of social commerce, its customer acquisition cost is lower than other platforms, such as Taobao and JD platforms. In 2017, the average customer cost of Taobao was 227 RMB and the average customer cost of JD was $226 \mathrm{RMB}$, but the average customer cost of Pinduoduo was less than 10 RMB [86]. Therefore, it can rescue the advertising fee. This advantage enables the platform to further offer lower prices to both supply-side and demand-side.

\section{Discussion}

This study analyses the change of the role of the platform provider in the platform development process. The conceptual model proposed in the previous section can be perfected, as shown in Figure 12.

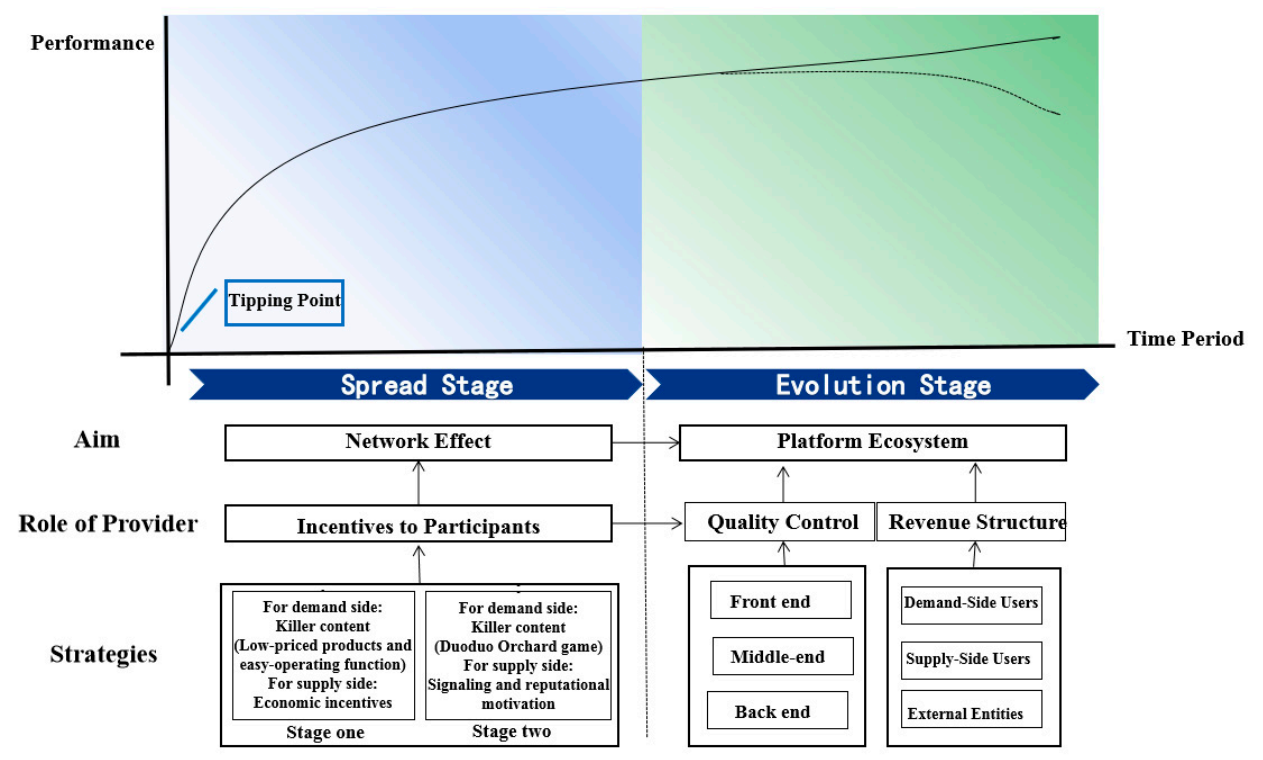

Figure 12. Revised conceptual model for social commerce platform development. 


\subsection{Central Question: How Do the Dynamic Roles of Platform Providers Change over Time?}

As indicated in the diagram, platform providers motivate all participants to enter the platform in spread stage. At evolution stage, the role of platform providers shifts to quality control and revenue structure design. This demonstrates that the development of Pinduoduo platform conforms to the original conceptual model, but at the same time, Pinduoduo platform also reflects its unique characteristics in various stages. Those characteristics do not appear in the original conceptual model and it is a supplement and refinement to the original conceptual model, which makes it more in line with the social commerce platform. From the case study, Pinduoduo has enabled rapid growth and realized the sustainable development of the platform by adopting different strategies and utilizing the advantage of social media. By analysing the case of Pinduoduo, this study provides deep investigation into the determinants of a successful social commerce platform. The sub-questions are discussed with findings from both theoretical and empirical studies as below.

\subsection{Sub-Question 1: How Do Incentives to Participants on the Social Commerce Platform in Spread Stage?}

Han [17] believes that incentives should effectively stimulate users to participate in the platform actively. In order to effectively incentive participants, targeted incentive strategies should be adopted for different users at the spread stage. In early spread stage, Pinduoduo platform attracts supply-side users by economic incentive. Meanwhile, Pinduoduo platform's killer content, which aimed to attract the demand-side user, is to provide low-priced products and easy-operating functions for the people at the bottom of the pyramid. In the latter spread stage, Pinduoduo platform attracts supply-side users by signaling, and reputations incentive and killer content which aimed to attract the demand-side user is Duoduo Orchard game. This is in line with the role of platform providers in incentives to participants proposed in the original conceptual model, and at the same time reflects the unique characteristics of the social commerce platform.

\subsection{Sub-Question 2: How Is It Best to Conduct Quality Control on the Social Commerce Platform?}

From the theoretical analysis, the quality control of a multilateral platform can be divided into soft certification and hard certification in terms of controlling intensity (Kim, 2016). The platform provider takes a mixed approach according to the particularity of the internal and external environment. In the case study, the principle of quality management design adopted by Pinduoduo is consistent with the matrix. Besides, Pinduoduo platform combines soft method with hard method, and emphasizes front-end quality control, middle-end quality control and back-end quality control.

\subsection{Sub-Question 3: How Is It Best to Apply a Suitable Revenue Structure on the Social Commerce Platform?}

Based on the existing theoretical basis, the platform providers intend to provide financial support to users according to the price sensitivity of participants. When both supply and demand users' need subsides, external entities such as sponsors and third-party manufacturers join the platform [16]. Revenue structure model of Pinduoduo is generated with the change of market demand and the dynamic capability of the platform provider, but price elasticity is still the most critical determinant of pricing strategy. This depends on the group character of the internet client and custom habit of the user. Based on practical observation, the revenue structure of Pinduoduo is consistent with the internal logic of a theoretical framework. Pinduoduo applied the sponsor-type revenue structure. In the meantime, Pinduoduo platform also shows the unique advantage of low customer acquisition cost. This advantage enables the platform to further offer favorable prices to both suppliers and buyers.

\section{Conclusions and Future Research}

A sustainable social eCommerce platform has great potential to contribute to the establishment of an inclusive business ecosystem. This research intends to propose this kind of platform business model 
based on the investigation of good practice in China. Lessons for success learned from Pinduoduo case study can be summarized in two aspects:

- Human-oriented platform design to stimulate potential demands. Traditional eCommerce platforms usually pay more attention to "goods" and "shopping malls" without consideration of the real needs of platform participant. Besides improving productivity and expanding sale channels, a 'human-oriented' design concept also encourages deep insight into the user's demands and even emotional experiences behind demands via digital technologies and social medias;

- Inclusive platform design to build business ecosystem. Diversification of Chinese society has resulted in the structural stratification of consumption. Different operating strategies should be adopted for different consumer groups. In general, consumers with high-level consumption pay more attention to consumption experience, and are willing to pay for brand premium and emotional value of products. BOP group, on the other hand, are still in the stage of price sensitivity, whose demands are often ignored by mainstream enterprises and platforms.

The successful experience of Pinduoduo platform can provide contributions and implications for the management in practice. In consideration to the research context, this research performs an analysis on a relatively successful stage-based platform development approach for a sustainable social eCommerce platform. Additionally, this can enlighten the current players in the market on how they might utilize the underlying rationales in framework to further development their platform business models, that could be especially applicable for new entrants and platform providers with limited capabilities. In the meantime, the framework could contribute effective thoughts to platform architecture and business model designs.

By doing the case study, several limitations are drawn as follows: The first limitation is that there is no third round of data collection, due to the restrictions in terms of research duration. The second limitation is the use of a single case study. Therefore, cross-case analysis to compare roles of platform providers in China and other countries, including both successful and failed platform operations, would be beneficial for the future research in this area.

Nowadays, Pinduoduo is integrating with Chinese manufacturers to become an Internet eCommerce platform with a full circle of "production + distribution + transaction + consumption". It also indicates the trend of social commerce platform development in China because of huge consumer demands created by this business model. Internet eCommerce platform will gradually drive the transformation of "made in China" to "created in China" and reverse the Internet as the unique path to an inclusive business ecosystem. In addition, with the development of mobile technologies, platforms become more 'decentralized' and 'fragmented' in terms of hardware and time. Continuous development digital technologies offer great opportunities for platform innovation. Therefore, the continuous research could be conducted on the question, 'what would be the role of platform providers to enable platform conduction and operation in the era of mobile Internet?'.

Author Contributions: Formal analysis: W.Z.; Conceptualization: Y.C.; Investigation: A.W.

Funding: This research was funded by Shaanxi Province Social Science Fund Project (2016R035) and Shaanxi Province Association for Science and Technology Project (E219060016).

Conflicts of Interest: The authors declare no conflict of interest. 


\section{Appendix A}

Table A1. Semi-structured interview protocol.

\begin{tabular}{cl}
\hline \multicolumn{1}{c}{ Introduction } & -Job description and function in the platform \\
\hline \multirow{2}{*}{ Platform Background } & $\begin{array}{l}\text {-Initiatives and value proposition in Pinduoduo platform? } \\
\text {-Technological capabilities of the platform providers? }\end{array}$ \\
\hline \multirow{3}{*}{ Incentives to Participants } & -Comment on the user growth pattern in Pinduoduo platform? \\
& -Comment on motivations for supply-side users? \\
& -Comment on motivations for demand-side users? \\
\hline \multirow{3}{*}{ Quality Management } & -Comment on balance between content quality and aggressive user growth \\
& -Explanations on the regulation architecture in Pinduoduo platform \\
& -Comments on the changes in quality regulation \\
& -Comparison among other platforms \\
\hline \multirow{3}{*}{ Revenue Structure } & -Explanations on revenue stream from demand-side users \\
& -Explanations on revenue stream from supply-side users \\
& -Explanations on revenue stream from cooperative users \\
& -Comments on revenue structure in Pinduoduo platform \\
\hline
\end{tabular}

(Notes: according to the job description of each respondent, the concentration of question area might be different. During the interviews, respondents are encouraged to give examples for certain strategies).

Table A2. Structure focus group interview protocol (for supply-side users).

\begin{tabular}{|c|c|}
\hline Question Number & Concrete Content \\
\hline Question 1: & $\begin{array}{l}\text {-How did you find the platform of Pinduoduo? } \\
\text {-Have you used other eCommerce platforms before? } \\
\text {-Why did you switch from other platforms to Pinduoduo platform? }\end{array}$ \\
\hline Question 2: & $\begin{array}{l}\text {-What motivates you to sell products on Pinduoduo platforms? } \\
\text {-What do you find most attractive about the platform? }\end{array}$ \\
\hline Question 3: & -How do you join in Pinduoduo platform and do you need to pay for it? \\
\hline Question 4: & $\begin{array}{l}\text {-How do you accumulate customers? } \\
\text {-What is the way you earn more from Pinduoduo platform? }\end{array}$ \\
\hline Question 5: & -Please provide a general comment on your usage experience in Pinduoduo platform? \\
\hline
\end{tabular}

(Notes: in terms of each question, the author should inspire every focus group member to respond, as well as motivating discussion between respondents).

Table A3. Structure focus group interview protocol (for demand-side users).

\begin{tabular}{|c|c|}
\hline Question Number & Concrete Content \\
\hline Question 1: & $\begin{array}{l}\text {-How did you find the platform of Pinduoduo? } \\
\text {-Have you used other eCommerce platforms before? } \\
\text {-Why did you switch from other platforms to Pinduoduo platform? }\end{array}$ \\
\hline Question 2: & $\begin{array}{l}\text {-What motivates you to buy goods on Pinduoduo platforms? } \\
\text {-In other words, how do you find this platform most attractive to you? }\end{array}$ \\
\hline Question 3: & $\begin{array}{l}\text {-How do you choose the products on the platform of Pinduoduo? } \\
\text {-Which aspect do you pay more attention to when choosing goods? }\end{array}$ \\
\hline Question 4: & -Are you satisfied with the quality of goods on the platform of Pinduoduo? \\
\hline Question 5: & -Please provide a general comment on your usage experience in Pinduoduo platform? \\
\hline
\end{tabular}

(Notes: in terms of each question, the author should inspire every focus group members to respond, as well as motivating discussion between respondents). 


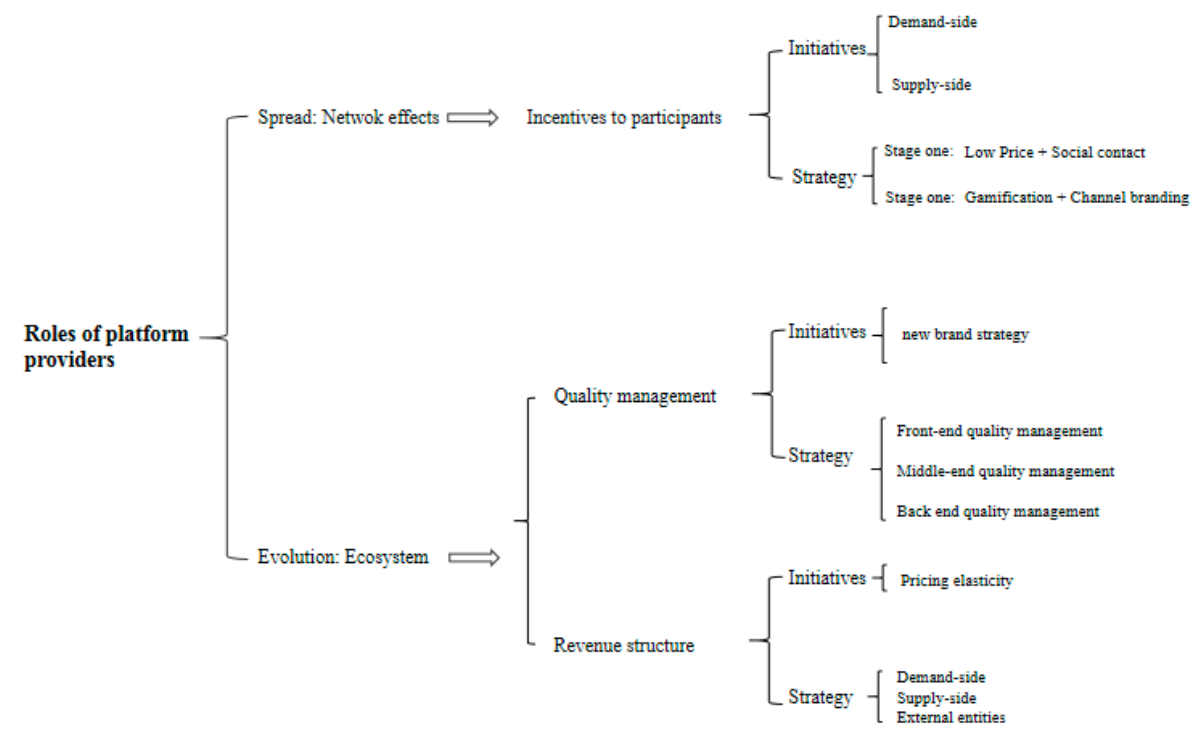

Figure A1. Coding schemes.

Table A4. Example of data unitizing sheet.

\begin{tabular}{|c|c|c|}
\hline Theme & Sub-Category & Sample of Coded Text \\
\hline $\begin{array}{c}\text { Incentives } \\
\text { to } \\
\text { participants }\end{array}$ & $\begin{array}{l}\text { Low cost products }+ \\
\text { Social network }\end{array}$ & 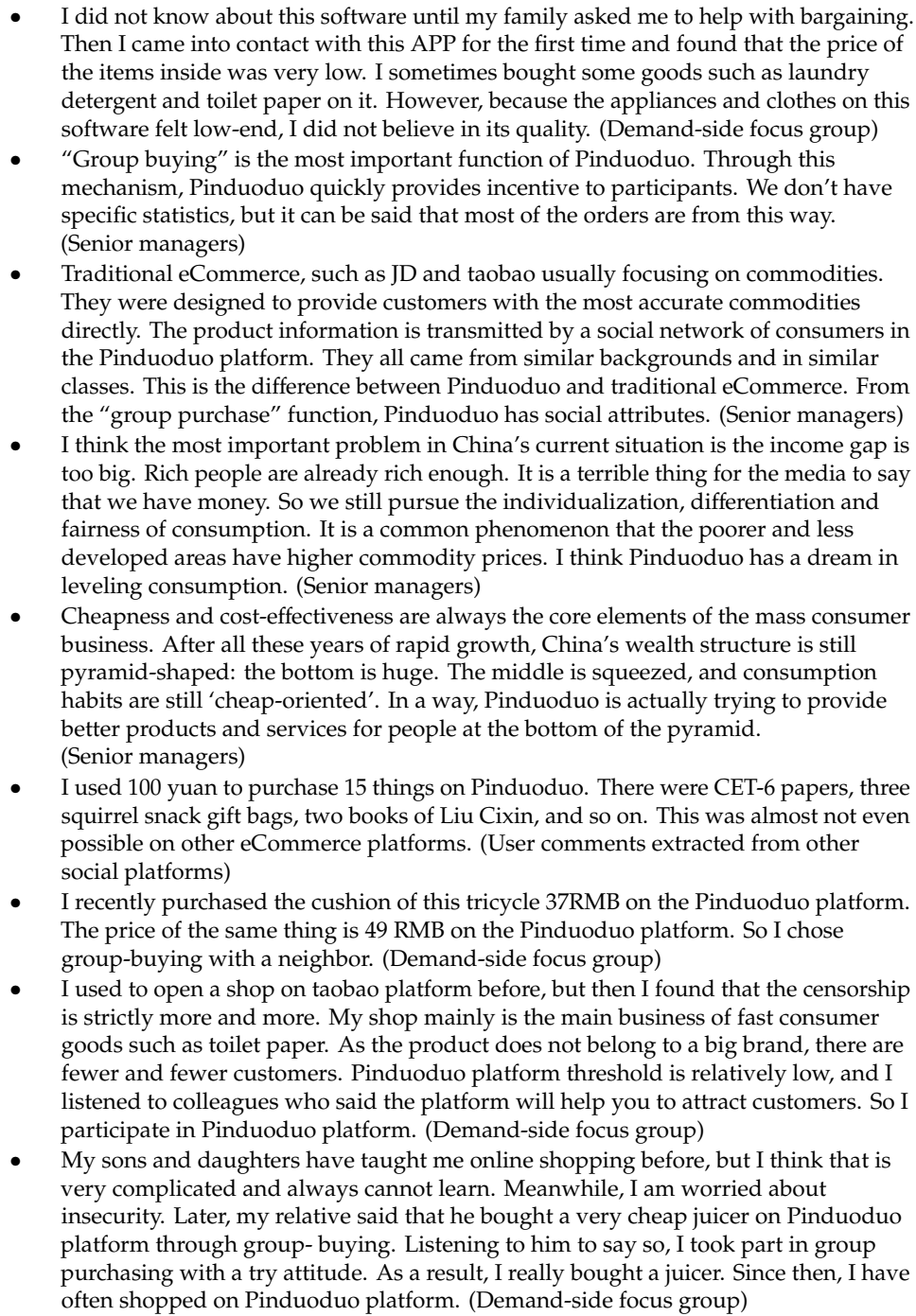 \\
\hline
\end{tabular}


Table A4. Cont.

\begin{tabular}{|c|c|c|}
\hline Theme & Sub-Category & Sample of Coded Text \\
\hline & $\begin{array}{c}\text { Gamification + Channel } \\
\text { brand }\end{array}$ & $\begin{array}{l}\text { - } \text { One of my friends has recently returned from Australia. When we were having a } \\
\text { party together that day, he saw me take out my mobile phone to water the tree on the } \\
\text { Pinduoduo platform, and he laughed at me for playing this kind of game. I told him } \\
\text { that when the fruit harvested in this orchard, Pinduoduo will really send a box of } \\
\text { fruit to your home. I set an alarm clock to water trees on time almost every day. He } \\
\text { feels particularly incredible, because before the game, the items in the game are never } \\
\text { linked to reality, the game props will not run to reality. He has never played this type } \\
\text { of game. I took him to play this game. Now he sets the alarm clock to water trees } \\
\text { with me every day. The duoduo orchards strengthen the interaction between people } \\
\text { and gave me a lot of fun. (Demand-side focus group) } \\
\text { I want to talk about Duoduo Orchard. In Duoduo Orchard, users can "water" fruit } \\
\text { trees and eventually get free fruit. This game facilitates people to actively participate, } \\
\text { which can give consumers more pleasure and attract more consumers to use } \\
\text { Pinduoduo APP. (Senior managers) } \\
\text { Previously, we were acquainted with a few large brands. But as the Chinese people } \\
\text { become richer and richer, numerous new brands emerge to meet their need. But these } \\
\text { brands were originally restricted by the monopoly of channels, and these brands can } \\
\text { not enter a large national supermarket. Online, traffic cost of taobao and Tmall stores } \\
\text { goes up all the way, and the cost of bid ranking can only be undertaken by } \\
\text { consumers. When it's cheap, no one knows. When it's high, a lot of potential } \\
\text { customers are lost. Under these circumstances, Pinduoduo platform provides a } \\
\text { growing ground for emerging brands. Because of this, Pinduoduo can provide } \\
\text { consumers with goods and products, and let consumers accept these emerging } \\
\text { brands without brand advantages through Pinduoduo platform. (Senior managers) }\end{array}$ \\
\hline \multirow{3}{*}{$\begin{array}{c}\text { Quality } \\
\text { management }\end{array}$} & $\begin{array}{l}\text { Front-end quality } \\
\text { management }\end{array}$ & \multirow{3}{*}{$\begin{array}{l}\text { - If an eCommerce enterprise want to participate in poverty alleviation work, the core } \\
\text { is to use the advantages of the Internet to solve the transportation of agricultural } \\
\text { products. At the beginning of the establishment of Pinduoduo platform, our team } \\
\text { found that the "Pinduoduo" model can gather huge consumer demand information } \\
\text { in a short time and quickly sell large quantities of current season agricultural } \\
\text { products. (Senior managers) } \\
\text { - With the development of the platform, the problem of counterfeit and inferior } \\
\text { commodities does occur in the platform. This problem is due to platform neglect of } \\
\text { quality management. In order to solve this problem, Pinduoduo has also learned } \\
\text { many of techniques from other eCommerce and formulated a very strict } \\
\text { anti-counterfeiting plan. Platform really should crack down on the manufacture and } \\
\text { sale of counterfeit or shoddy goods. This problem is harmful to the platform and } \\
\text { consumers. In the meanwhile, I also beg consumers to give Pinduoduo more time to } \\
\text { solve this problem. (Senior managers) } \\
\text { Pinduoduo will continue to promote the "New brand strategy", reduce the burden of } \\
\text { 1000 small and medium-sized enterprises. More than } 700 \text { factories have submitted } \\
\text { applications to participate in implementation of new brand strategy. More than } 90 \\
\text { factories have passed the tests. Some enterprises even proposed that even if they } \\
\text { could not participate in the New Brand Plan, they would like to live production } \\
\text { process in order to gain trust. (Senior managers) }\end{array}$} \\
\hline & $\begin{array}{l}\text { Middle-end quality } \\
\text { management }\end{array}$ & \\
\hline & $\begin{array}{l}\text { Back-end quality } \\
\text { management }\end{array}$ & \\
\hline $\begin{array}{l}\text { Revenue } \\
\text { structure }\end{array}$ & Pricing elasticity & $\begin{array}{l}\text { - Pinduoduo's revenue structure is similar to the revenue structure of taobao platform. } \\
\text { Platform gains income through offering marketing service (merchant advertisement) } \\
\text { and transaction service (payment and processing fee). However, Pinduoduo has } \\
\text { differentiated pricing strategies for demanders and suppliers. To ensure that the } \\
\text { platform has incentives for all parties, this is complicated and difficult to balance for } \\
\text { Pinduoduo at the present stage. (Senior managers) } \\
\text { The biggest advantage of Pinduoduo platform is they have a large quantity of } \\
\text { products. This advantage is being crucial for agricultural products. We buy garlic at } \\
5.75 \text { per catty, which is higher than the market price. If we add the costs of freight, } \\
\text { packaging and insurance, the profit is very low, sometimes even sell at a loss, but is } \\
\text { broadly profitable in normal time. My parents are ordinary farmers. Thus I hope we } \\
\text { can earn more money together relying on the platform. (Supplier focus groups) }\end{array}$ \\
\hline
\end{tabular}

\section{References}

1. Sami, A.; Hashim, K.F.; Yusof, S.A.M. Continuous use of social commerce: Its conceptual relation with E-WOM, commitment and trust. Int. Conf. Appl. Sci. Technol. 2016, 1761, 20095.

2. Kirilka, V.; Stukas, T. Strategic Renewal in Retail Companies by Means of Social e-Commerce. 2012. Available online: http://hj.diva-portal.org/smash/get/diva2:528850/FULLTEXT01.pdf (accessed on 3 November 2019).

3. Kim, Y.; Srivastava, J. Impact of social influence in e-commerce decision making. In Proceedings of the Ninth International Conference on Electronic Commerce, Minneapolis, MN, USA, 19-22 August 2007; ACM: New York, NY, USA, 2007; pp. 293-302. 
4. China Internet Association. Report on the Development of China's Social E-Commerce Industry in 2018. Available online: http://baogao.chinabaogao.com/hulianwang/355655355655.html (accessed on 6 August 2018).

5. UBS Evidence Lab. Pinduoduo Development Report. Available online: https://www.guancha.cn/ChanJing/ 2019_03_12_493245.shtml (accessed on 12 March 2019).

6. Kim, J. The Platform Business Model and Strategy: A Dynamic Analysis of the Value Chain and Platform Business. Ph.D. Thesis, The University of Manchester, Manchester, UK, 2016.

7. Armstrong, M. Competition in two-sided markets. RAND J. Econ. 2006, 37, 668-691. [CrossRef]

8. Rochet, J.C.; Tirole, J. Two-sided markets: A progress report. RAND J. Econ. 2006, 37, 645-667. [CrossRef]

9. Evans, D.S.; Hagiu, A.; Schmalensee, R. Invisible Engines: How Software Platforms Drive Innovation and Transform Industries; MIT Press: Cambridge, MA, USA, 2008.

10. Zhang, X.; Zhao, J. Platform strategy and innovation under the background of new industrial revolution: A case study of haier's platform strategy. Sci. Sci. Manag. S.E T. 2015, 3, 77-86. (In Chinese)

11. Malone, T.W.; Yates, J.; Benjamin, R.I. Electronic Markets and Electronic Hierarchies; Oxford University Press: Oxford, UK, 1987.

12. Bakos, Y. The emerging role of electronic marketplaces on the internet. Commun. ACM 1998, 41, 35-42. [CrossRef]

13. Willis, J.L. What impact will e-commerce have on the US economy? Econ. Rev. 2004, 89, 53-73.

14. Barkley, D.L.; Lamie, R.D.; Markley, D.M. Case Studies of E-Commerce in Small and Medium-sized Enterprises: A Review of the Literature; University Center for Economic Development Working Paper; Clemson University: Clemson, SC, USA, 2007; Volume 10, p. 16.

15. Rikkiev, A.; Mäkinen, S.J. Technology convergence and intercompany R\&D collaboration: Across business ecosystems boundaries. Int. J. Innov. Technol. Manag. 2013, 10, 1350009.

16. Cai, N.; Wang, J.; Yang, D. Platform envelopment strategy decision and competitive advantage building under the background of industrial convergence-A case study of ZDM. China Ind. Econ. 2015, 5, 96-109. (In Chinese)

17. Kim, J. The platform business model and business ecosystem: Quality management and revenue structures. Eur. Plan. Stud. 2016, 24, 1-20. [CrossRef]

18. Han, J.; Cho, O. Platform business eco-model evolution: Case study on kakaotalk in Korea. J. Open Innov. Technol. Mark. Complex. 2015, 1, 6-14. [CrossRef]

19. Evans, D.S. How Catalysts Ignite: The Economics of Platform-Based Start-Ups. In Platform, Markets and Innovation; Edward Elgar Publishing: Cheltenham, UK, 2009; pp. 99-128.

20. Jascanu, N.; Jascanu, V.; Nicolau, F. A New Approach to E-Commerce Multi-Agent Systems; Dunarea de Jos University of Galati: Galati, Romania, 2007; Available online: http://www.arthra.ugal.ro/handle/123456789/ 3882 (accessed on 3 November 2019).

21. Dennison, G.; Bourdage-Braun, S.; Chetuparambil, M. Social Commerce Defined; White Paper 23747; IBM Systems Technology Group: Research Triangle Park, NC, USA, 2009.

22. Kim, D. Under what conditions will social commerce business models survive? Electron. Commer. Res. Appl. 2013, 12, 69-77. [CrossRef]

23. Culnan, M.J.; McHugh, P.J.; Zubillaga, J.I. How large US companies can use Twitter and other social media to gain business value. MIS Q. Exec. 2010, 9, 124-259.

24. Ickler, H.; Schülke, S.; Wilfling, S.; Baumöl, U. New challenges in e-commerce: How social commerce influences the customer process. 2009. Available online: http://citeseerx.ist.psu.edu/viewdoc/download? doi=10.1.1.460.5449\&rep=rep1\&type=pdf (accessed on 3 November 2019).

25. Marsden, P. How Social Commerce Works: The Social Psychology of Social Shopping. 2009. Available online: http://www.slideshare.net/paulsmarsden/social-psychology-of-social-shopping-howsocial-commerce-works (accessed on 3 November 2019).

26. Liang, T.P.; Turban, E. Introduction to the special issue social commerce: A research framework for social commerce. Int. J. Electron. Commer. 2011, 16, 5-14. [CrossRef]

27. Zheng, X.; Cheung, C.M.K.; Lee, M.K.O.; Liang, L. Building brand loyalty through user engagement in online brand communities in social networking sites. Inf. Technol. People 2015, 28, 90-106. [CrossRef]

28. Boudreau, K.J.; Hagiu, A. Platform rules: Multi-sided platforms as regulators. Platf. Mark. Innov. 2009, 1, 163-191. 
29. Gawer, A.; Cusumano, M.A. Platform Leaders. In MIT Sloan Management Review; MIT Sloan School of Management: Boston, MA, USA, 2008; pp. 68-75.

30. Boudreau, K.J.; Jeppesen, L.B. Unpaid crowd complementors: The platform network effect mirage. Strateg. Manag. J. 2015, 36, 1761-1777. [CrossRef]

31. Rysman, M. Competition between Networks: A Study of the Market for Yellow Pages; Boston University: Boston, MA, USA, 2000.

32. Lee, S.M.; Kim, T.; Noh, Y.; Lee, B. Success factors of platform leadership in web 2.0 service business. Serv. Bus. 2010, 4, 89-103. [CrossRef]

33. Tomsen, M.L.; Wu, K.L.; Foreword By-Mathison, D. Killer Content: Strategies for Web Content and E-Commerce; Addison-Wesley Longman Publishing Co., Inc.: Boston, MA, USA, 2000.

34. Curty, R.G.; Zhang, P. Social commerce: Looking back and forward. Proc. Am. Soc. Inf. Sci. Technol. 2011, 48, 1-10. [CrossRef]

35. Zhu, F.; Iansiti, M. Dynamics of Platform Competition: Exploring the Role of Installed Base, Platform Quality and Consumer Expectations; Division of Research; Harvard Business School: Boston, MA, USA, 2007.

36. Ba, S.; Whinston, A.; Zhang, H. Building trust in the electronic market through an economic incentive mechanism. In Proceedings of the 20th international conference on Information Systems (ICIS 1999), Charlotte, NC, USA, 12-15 December 1999.

37. Ward, M.R.; Lee, M.J. Internet shopping, consumer search and product branding. J. Prod. Brand Manag. 2000, 9, 6-20. [CrossRef]

38. Akerlof, G.A. The market for lemons: Quality and the market mechanism. Q. J. Econ. 1970, 84, 488-500. [CrossRef]

39. Hagiu, A. Multi-sided platforms: From microfoundations to design and expansion strategies. In Harvard Business School Strategy Unit Working Paper; Harvard Business School Strategy Unit: Boston, MA, USA, 2009; pp. 9-115.

40. Rochet, J.C.; Tirole, J. Platform competition in two-sided markets. J. Eur. Econ. Assoc. 2003, 1, 990-1029. [CrossRef]

41. Rochet, J.C.; Tirole, J. Two-sided markets: An overview. In Institut d'Economie Industrielle Working Paper; MIT Press: Cambridge, MA, USA, 2004.

42. Caillaud, B.; Jullien, B. Chicken and Egg: Competition among Intermediation Service Providers [EB/OL]; IDEI Working Paper; WILEY-BLACKWELL: Hoboken, NJ, USA, 2002.

43. Eisenmann, T.; Parker, G.; Van Alstyne, M.W. Strategies for two-sided markets. Harv. Bus. Rev. 2006, 84, 92.

44. Dubosson-Torbay, M.; Osterwalder, A.; Pigneur, Y. E-business model design, classification, and measurements. Thunderbird Int. Bus. Rev. 2002, 44, 5-23. [CrossRef]

45. Casadesus-Masanell, R.; Zhu, F. Business model innovation and competitive imitation: The case of sponsor-based business models. Strateg. Manag. J. 2013, 34, 464-482. [CrossRef]

46. Mahadevan, B. Business models for Internet-based e-commerce: An anatomy. Calif. Manag. Rev. 2000, 42, 55-69. [CrossRef]

47. Langley, P.; Leyshon, A. Platform capitalism: The intermediation and capitalisation of digital economic circulation. Financ. Soc. 2017, 3, 11-31. [CrossRef]

48. Klein, B.; Leffler, K. The role of price in guaranteeing quality. J. Political Econ. 1981, 89, 615-641. [CrossRef]

49. Rad, A.A.; Benyoucef, M. A model for understanding social commerce. J. Inf. Syst. Appl. Res. 2011, 4, 63-73.

50. Moore, J. The rise of a new corporate form. Wash. Q. 1998, 21, 167-181. [CrossRef]

51. Roundy, P.; Bradshaw, M.; Brockman, B. The emergence of entrepreneurial ecosystems: A complex adaptive systems approach. J. Bus. Res. 2018, 86, 1-10. [CrossRef]

52. Garnsey, E.; Leong, Y.Y. Combining Resource-Based and Evolutionary Theory to Explain the Genesis of Bio-networks. Ind. Innov. 2008, 15, 669-686. [CrossRef]

53. Sheriff, M.; Muffatto, M. The present state of entrepreneurship ecosystems in selected countries in Africa. Afr. J. Econ. Manag. Stud. 2015, 6, 17-54. [CrossRef]

54. Motoyama, Y.; Knowlton, K. Examining the connections within the startup ecosystem: A case study of St. Louis. Entrep. Res. J. 2017, 7, 1-32. [CrossRef]

55. Mitchell, J.; Treviranus, J. Inclusive Design in Ecosystems. In E-Health Two-Sided Markets: Implementation and Business Models; Elsevier: Amsterdam, The Netherlands, 2017; pp. 43-61. 
56. Gupta, A.; Dey, A.; Singh, G. Connecting corporations and communities: Towards a theory of social inclusive open innovation. J. Open Innov. Technol. Mark. Complex. 2017, 3, 17. [CrossRef]

57. Siddiqi, A.; Collins, R.D. Sociotechnical systems and sustainability: Current and future perspectives for inclusive development. Curr. Opin. Environ. Sustain. 2017, 24, 7-13. [CrossRef]

58. Altman, E.J.; Tripsas, M. Product to platform transitions: Organizational identity implications. In The Oxford Handbook of Creativity, Innovation, and Entrepreneurship; Oxford University Press: Oxford, UK, 2015; pp. 379-394.

59. Hagiu, A.; Wright, J. Multi-sided platforms. Int. J. Ind. Organ. 2015, 43, 162-174. [CrossRef]

60. Hyde, K.F. Recognising deductive processes in qualitative research. Qual. Mark. Res. Int. J. 2000, 3, 82-90. [CrossRef]

61. Ezzy, D. Qualitative Analysis; Routledge: London, UK, 2013.

62. Yin, R.K. Case Study: Design and Methods; Sage Publications: Newbury Park, CA, USA, 1994.

63. Miller, D.C. Guides to Methods and Techniques of Collecting Data in Library, Field and Laboratory. In Handbook of Research Design and Social Measurement; SAGE Publications: Newbury Park, CA, USA, 2002; pp. 159-168.

64. Evergrande Research Institute. New Economy Series Research: Pinduoduo, a Representative of the New Generation of E-Commerce Model, Rise Against the Trend and Shake the Industry Pattern. Available online: https://www.useit.com.cn/thread-22351-1-1.html (accessed on 26 July 2018).

65. Denzin, N.K. Interpretive Biography: Qualitative Research Methods Series 17; Sage: Thousand Oaks, CA, USA; London, UK, 1989; Volume 23.

66. Trochim, W.M. An introduction to concept mapping. Eval. Program Plan. 1989, 12, 1-16. [CrossRef]

67. Pinduoduo. The Listed Prospectus of "Pinduoduo" in 2018. Available online: https://www.useit.com.cn/ thread-19905-1-1.html (accessed on 31 July 2018).

68. Prahalad, C.K.; Prahalad, C.K. Strategies for the bottom of the economic pyramid: India as a source of innovation. Reflect. Sol J. 2002, 3, 6-17. [CrossRef]

69. Karnani, A. Misfortune at the Bottom of the Pyramid. Greener Manag. Int. 2006, 51, 99-110. [CrossRef]

70. Morgan, R.M.; Hunt, S.D. The commitment-trust theory of relationship marketing. J. Mark. 1994, 58, $20-38$. [CrossRef]

71. Day, G.S. Managing market relationships. J. Acad. Mark. Sci. 2000, 28, 24-30. [CrossRef]

72. Mangold, W.G.; Faulds, D.J. Social media: The new hybrid element of the promotion mix. Bus. Horiz. 2009, 52, 357-365. [CrossRef]

73. Barki, E.; Parente, J. Consumer Behaviour of the Base of the Pyramid Market in Brazil. Greener Manag. Int. 2006, 2006, 11-23. [CrossRef]

74. Haythornthwaite, C. Social networks and online community. In The Oxford Handbook of Internet Psychology; Oxford University Press: Oxford, UK, 2007; pp. 121-137.

75. Huotari, K.; Hamari, J. Defining gamification: A service marketing perspective. In Proceeding of the 16th International Academic MindTrek Conference, Tampere, Finland, 3-5 October 2012; ACM: New York, NY, USA, 2012; pp. 17-22.

76. Hofacker, C.F.; De Ruyter, K.; Lurie, N.H.; Manchanda, P.; Donaldson, J. Gamification and mobile marketing effectiveness. J. Interact. Mark. 2016, 34, 25-36. [CrossRef]

77. Klein, S.; Loebbecke, C. The transformation of pricing models on the web: Examples from the airline industry. In Proceedings of the 13th International Bled Electronic Commerce Conference, Bled, Slovenia, 19-21 June 2000.

78. Kihlstrom, R.E.; Riordan, M.H. Advertising as a Signal. J. Political Econ. 1984, 92, 427-450. [CrossRef]

79. Milgrom, P.; Roberts, J. Price and advertising signals of product quality. J. Political Econ. 1986, 94, 796-821. [CrossRef]

80. Chu, W.; Chu, W. Signaling quality by selling through a reputable retailer: An example of renting the reputation of another agent. Mark. Sci. 1994, 13, 177-189. [CrossRef]

81. Banerjee, A.V.; Duflo, E. The economic lives of the poor. J. Econ. Perspect. 2007, 21, 141-168. [CrossRef] [PubMed]

82. Wu, X.; Li, L. Recognition the declining manufacturing industries and growing manufacturing industries in china. Stud. Sci. Sci. 2010, 10, 1476-1483. 
83. Hammond, A.L.; Kramer, W.J.; Katz, R.S.; Tran, J.T.; Walker, C. The Next Four Billion: Market Size and Business Strategy at the Base of the Pyramid; World Resources Institute: Washington, DC, USA, 2007.

84. Zhang, C.; Wu, X. Micro mechanism and opportunity source and of inclusive growth: Entrepreneurship and bottom of the pyramid (bop). Sci. Technol. Prog. Policy 2013, 9, 1-4.

85. Adner, R.; Zemsky, P. A demand-based perspective on sustainable competitive advantage. Strateg. Manag. J. 2006, 27, 215-239. [CrossRef]

86. Citic Construction Securities. On the Growth and Controversy of Pinduoduo, a Leading Social E-Commerce Enterprise. 2018. Available online: http://www.ewenku.net/docs/d5d1ae88015c50 (accessed on 9 August 2018).

C 2019 by the authors. Licensee MDPI, Basel, Switzerland. This article is an open access article distributed under the terms and conditions of the Creative Commons Attribution (CC BY) license (http://creativecommons.org/licenses/by/4.0/). 